\title{
Qualidade do espaço residencial: efeitos da verticalização no bairro de Tambaú, na cidade de João Pessoa (PB) ${ }^{1}$
}

\author{
Quality of residential space: effects of verticalization on the \\ neighborhood of Tambaú, in the city of João Pessoa (PB)
}

Fabiana de Albuquerque Silveira[a], José Augusto Ribeiro da Silveira ${ }^{[b]}$

[a] Mestre em Arquitetura e Urbanismo pelo Programa de Pós-Graduação em Arquitetura e Urbanismo (PPGAU) da Universidade Federal da Paraíba (UFPB), João Pessoa, PB - Brasil, e-mail: fabialbuquerque@hotmail.com

[b] Doutor em Desenvolvimento Urbano, professor associado do Departamento de Arquitetura da Universidade Federal da Paraíba (UFPB), João Pessoa, PB - Brasil, e-mail: ct.laurbe@gmail.com

\section{Resumo}

A pesquisa tem como objetivo analisar o impacto da verticalização na qualidade do espaço residencial urbano, utilizando como objeto empírico um recorte espacial de quatro quarteirões localizados no bairro de Tambaú, na zona leste da cidade de João Pessoa (PB). 0 estudo foi desenvolvido em 2011 e o bairro em questão foi escolhido por estar passando por um processo de verticalização. Foi utilizada como base metodológica de avaliação a ferramenta denominada Qualidade do Espaço Residencial (QER), que foi adaptada à área de estudo, resultando na aplicação do Índice de Qualidade do Espaço da Habitação (QEH Adaptado). Foram analisadas questões que compõem os indicadores do Índice QEH Adaptado, como: estado de conservação dos edifícios, tipo edilício, qualidade e fruibilidade do espaço pertinente, proximidade à orla marítima, interferência do tráfego de veículos e exposição solar. 0 estudo demonstrou que a verticalização e o consequente adensamento populacional podem vir a interferir na qualidade do espaço urbano residencial e, consequentemente, na qualidade de vida dos habitantes do local onde esse processo se insere, dentre outras razões, por aumentar o tráfego de veículos e a demanda por estacionamentos, alterar a presença de cobertura vegetal e interferir na forma de exposição solar.

Palavras-chave: Qualidade de vida. Qualidade do espaço residencial (QER). Qualidade do espaço da habitação (QEH). Verticalização. Adensamento populacional.

\footnotetext{
${ }^{1}$ Este artigo foi elaborado a partir do livro intitulado Impacto da verticalização na qualidade do espaço residencial (Novas Edições Acadêmicas - NEA, 2014), dos mesmos autores do presente trabalho.
} 


\section{Abstract}

The research aims to analyze the impact of uprighting on the quality of urban residential space, using as empirical object spatial snip of four blocks located in the neighborhood of Tambaú, on the east zone of João Pessoa city. The study was developed over in 2011 and the neighborhood in question was chosen because it is undergoing a uprighting process. It was used as a assessment methodological basis the adaptated tool residential space quality (RSQ), resulting in the implementation of the Housing Space Quality Index (Adapted HSQ). It was analyzed the issues that compose the Adapted Index indicators HSQ as: condition of the buildings, quality of relevant space, proximity to the waterfront, interference from vehicle traffic and solar exposure. The research demonstrated that the uprighting and consequent population density might interfere in the quality of urban residential space and consequently in the quality of life of the inhabitants of the place where this process takes place, among other reasons for increasing vehicle traffic and demand for parking; change the presence of vegetation and interfere in the form of solar exposure.

Keywords: Quality of life. Quality of residential space (QER). Quality of housing space (QEH).

Uprighting. Population density.

\section{Introdução}

As pessoas estão constantemente em busca de melhor qualidade de vida, e a moradia e sua localização são um dos principais elementos para medição dessa qualidade. Como resultado da busca constante pelas melhores localizações, o adensamento populacional proporcionado pelos agentes produtores do espaço urbano acaba por se tornar uma realidade, através do processo de verticalização.

De acordo com Giménez (2007, p. 17),

0 processo de verticalização é entendido como a "criação de novos solos", os quais estão sobrepostos, constituindo um local de moradia ou de trabalho, distribuídos em diversos andares, possibilitando um maior número populacional exercendo as mais diferentes funções.

De acordo com Acioly Jr. e Davidson (1998), urbanistas e planejadores urbanos se defrontam com o dilema sobre o tamanho, a forma e o padrão de crescimento que as cidades devem assumir. Como seria a cidade ideal? Seria a cidade compacta, com maiores densidades populacionais, menores distâncias a serem percorridas e sustentável? Ou seria a cidade espraiada, menos densa, amena e "tranquila" um padrão a ser seguido? Os autores explicam que, qualquer que seja a escolha, as soluções mencionadas trazem consigo uma série de impactos para o meio ambiente, para a qualidade, intensidade, singularidade de vida e convívio urbanos.
No âmbito do debate crítico sobre a qualidade das cidades verticalizadas e adensadas versus cidades horizontalizadas e menos densas, o presente trabalho aborda a questão da qualidade do espaço residencial, sendo esse o local onde se desenvolve o cotidiano dos moradores de uma cidade, cujo principal indicador socioambiental é a habitação verticalizada. 0 estudo do tema em questão se mostra importante pelo fato de a verticalização se fazer cada vez mais presente nas grandes e médias cidades brasileiras e por poder interferir na dinâmica e na qualidade do espaço residencial onde esse processo se insere (KIEFER, 2006; RYKWERT, 2004).

0 trabalho tem como objetivo analisar o impacto da verticalização na qualidade do ambiente construído, sob os aspectos da qualidade do espaço da habitação (QEH Adaptado), a partir do método de avaliação da Qualidade do Espaço Residencial (QER) estudado por Socco et al. (2002) e Scussel (2007).

Para a efetivação do estudo de caso foram selecionados quatro quarteirões do bairro de Tambaú, localizado na zona leste da cidade de João Pessoa (PB), sendo dois deles caracterizados predominantemente por construções térreas ou de, no máximo, dois pavimentos, e outros dois caracterizados pela produção de construções habitacionais verticalizadas. Pretendeu-se, com a escolha desses padrões construtivos diferenciados, fazer uma análise comparativa entre os quarteirões e observar a interferência passível de ser identificada na qualidade do espaço residencial de quarteirões que apresentam 
maior índice de verticalização, analisando a qualidade da habitação e de seu contexto.

O bairro de Tambaú é uma das áreas da cidade de João Pessoa que passa por maiores transformações no padrão construtivo de suas edificações, sendo caracterizado por construções habitacionais cada vez mais verticalizadas.

Estendendo-se a aplicação do método, com foco mais específico, comparado e diferenciado daquele originalmente adotado, este paper reforça a potencialidade da ferramenta, contribuindo para a discussão científica do padrão físico-territorial da cidade.

\section{Importância da análise do espaço residencial}

No espaço residencial se desenvolve grande parte do cotidiano dos moradores de uma cidade, se mostrando importante a análise da malha urbana que estrutura esse espaço, considerando a relação que as edificações residenciais mantêm com o seu entorno. De acordo com Pedro (2002, p. 20) “[...] a habitação influencia sobre múltiplos aspectos o dia a dia dos moradores, marcando a sua qualidade de vida e as suas expectativas e possibilidades de desenvolvimento futuro".

O parâmetro para avaliar a qualidade de um espaço residencial está diretamente ligado ao parâmetro de qualidade de vida. Definir qualidade de vida, no entanto, conduz a um quadro complexo de possíveis formulações. Segundo Scussel (2007), esse é um conceito carregado de juízo de valor e de caráter subjetivo, construído a partir das condições socioeconômico-culturais de indivíduos ou comunidades.

Uma das definições de qualidade de vida explica que ela é caracterizada pela soma de variadas condições, dentre elas a condição ambiental, e inclui "[...] gestão territorial que assegure ar limpo, higidez ambiental, equipamentos coletivos urbanos" (HERCULANO, 2000, p. 22) e "a disponibilidade de espaços naturais amenos urbanos, bem como a preservação de ecossistemas naturais" (LEE; JE; BYUN, 2011, p. 1184-1194).

Autores como Caro e Rivas (1990) e Nucci (2008) consideram que a verticalização do espaço urbano pode ocasionar mudanças no meio físico, acarretando impactos ambientais no clima urbano, na drenagem, na cobertura vegetal, no conforto térmico, no sossego público, na mobilidade e na qualidade do ar. De acordo com os mesmos autores, a verticalização aumenta a superfície impermeabilizada, o tráfego de veículos e, consequentemente, a poluição; surge o sombreamento que causa contrastes térmicos entre a parte sombreada e a ensolarada. A verticalização também pode promover a sensação de "estreiteza" das ruas e o estrangulamento dos pátios e pode ocasionar a falta de privacidade pela proximidade das edificações (LEE, 2011).

0 processo de verticalização se apresenta como uma questão polêmica, na qual são observados aspectos negativos e positivos. Autores como Rueda (1996) convergem para a defesa de uma cidade dita mais sustentável, compacta e diversa, concentrada e densificada, que reúne princípios como o da multiplicidade de usos e atividades, que encurta distâncias e estimula o desenvolvimento de relações locais. A proposta de cidades compactas é uma contribuição europeia, que visa, sobretudo, a reduzir os custos da construção material, de infraestruturas, propiciando circulação mais eficiente e menos dispendiosa, e reduzindo a necessidade de expansão sobre novas áreas naturais. Essa proposta permite também o pedestrianismo, devido às menores distâncias, a convivência social, a valorização dos centros tradicionais e a administração mais racional da circulação interna, diferentemente de cidades espraiadas, de crescimento extensivo (MYERS, 1990; YEANG, 2002).

Dentre os críticos da cidade compacta e verticalizada, como Nucci (2008), um dos argumentos mais utilizados tem sido o da suposta baixa qualidade de vida urbana motivada por uma possível escassez de espaços abertos e naturais, no espaço intraurbano, e impactos negativos sobre a infraestrutura e os serviços instalados.

Um dos responsáveis pelo nível de qualidade no ambiente urbano se refere à combinação entre a morfologia de um espaço e a quantidade de pessoas que o ocupam (PANERAI et al., 2008). Estudiosos da área de planejamento urbano apresentam opiniões diversas sobre qual é a densificação populacional ideal para áreas urbanas e como elas devem ocorrer. Alves (2011) aponta inexistência de consenso acerca do que pode ser considerado alta, média e baixa densidade, pois esses conceitos variam de acordo com o contexto territorial e cultural no qual se inserem. Gilham (2002) esclarece que a densidade populacional menor que 25 habitantes por hectare é geralmente considerada como baixa, sendo, no entanto, um 
valor que serve de referência, sobretudo, ao modelo norte-americano e australiano, uma vez que na Europa os valores de baixa densidade podem ser considerados aqueles inferiores a 50 habitantes por hectare e, no que diz respeito aos países asiáticos, abaixo de 100 habitantes por hectare. 0 contexto cultural, econômico e o desenho urbano influenciam a percepção de densidade populacional e construtiva.
Na oferta de empreendimentos verticalizados estão inclusos mais segurança e localizações acessíveis e dotadas de infraestrutura urbana, com amenidades paisagísticas, como as orlas marítimas das cidades brasileiras, a exemplo do caso de João Pessoa. Um dos bairros mais atrativos nesse processo é o de Tambaú, predominantemente residencial e localizado em uma área considerada "nobre" da cidade. A Figura 1 apresenta a verticalização no local.

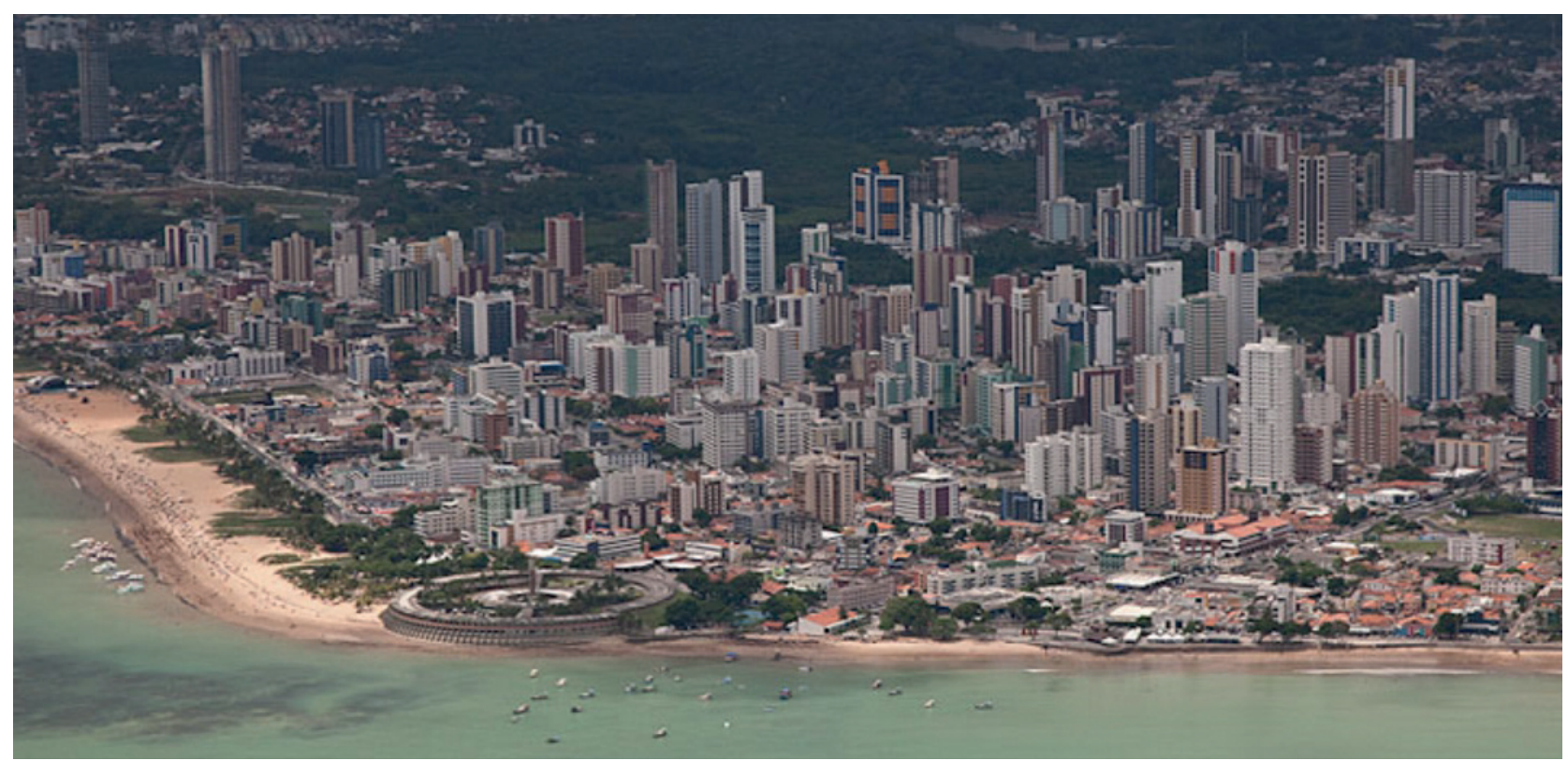

Figura 1 - Fotografia aérea do bairro de Tambaú, mostrando o processo de verticalização no local Fonte: SILVEIRA, 2011; VASCONCELLOS, 2008.

\section{Estrutura do índice QEH (Qualidade do Espaço da Habitação) adaptado}

Para a efetivação da pesquisa foi utilizada como base metodológica uma ferramenta aplicável à escala que se pretendeu analisar (em nível de quarteirão): o Índice de Qualidade do Espaço Residencial (QER), aplicado por Scussel (2007) a partir de Socco et al. (2002), que desenvolveu o índice para analisar a qualidade do lugar de morar em Reggio Emilia, na Itália. 0 índice é calculado para cada lote urbano, sendo feitas, aqui, adaptações para melhor aproveitamento da ferramenta, resultando no Índice de Qualidade doEspaço da Habitação Adaptado. Os quarteirões escolhidos para o estudo de caso são apresentados na Figura 2 e foram identificados por: A, B, C e D, somando 99 lotes edificados pesquisados.
O Índice QER, de acordo com Scussel (2007), é composto por dois outros índices: o Índice de Qualidade do Espaço da Habitação (QEH) e o Índice de Qualidade do Espaço dos Serviços Sociais Básicos (QES). Cada um deles resulta da junção de subíndices. A obtenção de cada um dos subíndices mencionados é realizada por meio da aferição de um conjunto de indicadores que participam com uma ponderação específica no cálculo do respectivo subíndice, conforme o nível de importância que lhes é atribuído, sendo baseada numa matriz de confronto de pares. Dessa matriz, resulta o cálculo dos pesos atribuídos a cada indicador (k), em uma escala normalizada de zero a um. No entanto, Scussel (2007) explica que se poderia arbitrar ponderações para os indicadores de outra maneira, pois todos trazem implícito um juízo de valor. A técnica empregada consiste no confronto, dois a dois, dos diferentes indicadores 


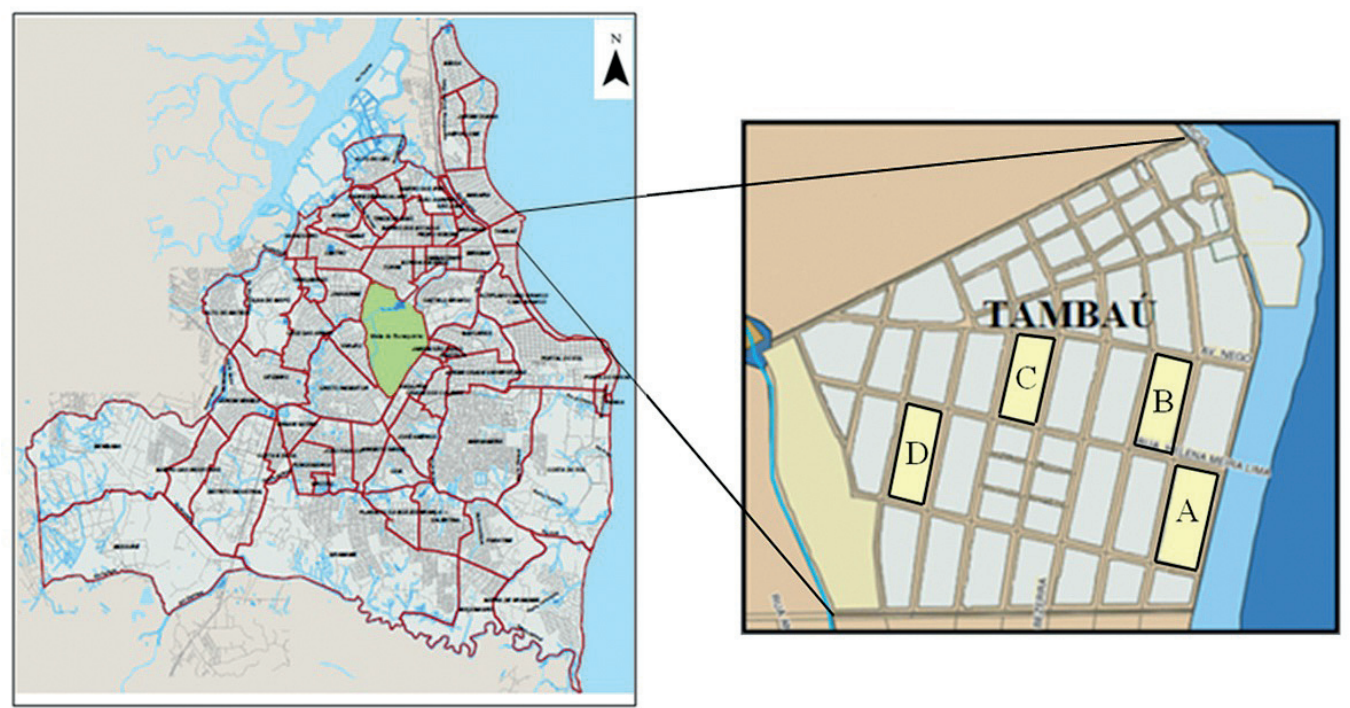

Figura 2 - Cidade de João Pessoa, com destaque para o bairro de Tambaú e os quarteirões pesquisados Fonte: PREFEITURA MUNICIPAL DE JOÃO PESSOA, 2001, editado pelos autores.

Tabela 1 - Matriz de confronto de pares de determinação das ponderações dos indicadores (K) do índice QH

\begin{tabular}{lllll}
\hline ÍNDICE & $\mathbf{H c}$ & $\mathbf{H t}$ & $\mathbf{H a}$ & $\mathbf{H p}$ \\
\hline $\mathbf{H c}$ & $\mathbf{5 0}$ & 80 & 65 & 55 \\
\hline $\mathbf{H t}$ & 20 & $\mathbf{5 0}$ & 60 & 70 \\
\hline $\mathbf{H a}$ & 35 & 40 & $\mathbf{5 0}$ & 75 \\
\hline $\mathbf{H p}$ & 45 & 30 & 25 & $\mathbf{5 0}$ \\
\hline
\end{tabular}

Fonte: SCUSSEL, 2007.

dispostos na matriz. A Tabela 1 apresenta um exemplo da matriz de confronto de pares.

Foi utilizado, para o desenvolvimento da pesquisa, o Índice QER de forma parcial, sendo aproveitado o Índice de Qualidade do Espaço da Habitação (QEH). As adaptações realizadas referem-se à criação e ao acréscimo de indicadores que se mostraram pertinentes ao desenvolvimento da pesquisa: os indicadores $\mathrm{Ho}$ e $\mathrm{Cq}$, os quais contribuíram para a aplicação do método em um ambiente construído diferentemente dos estudos originais, o que constitui uma das contribuições do trabalho. A estrutura do Índice QEH Adaptado

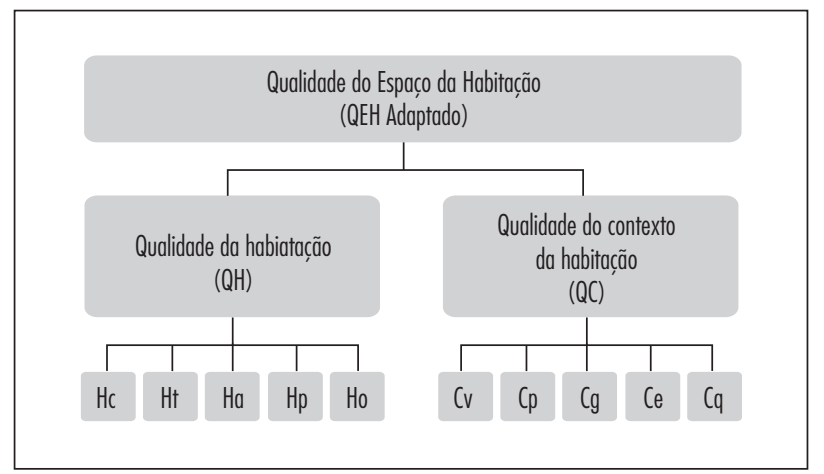

Figura 3 - Estrutura de avaliaç̦ão da Qualidade do Espaço da Habitação Adaptado Fonte: CUSSEL, 2007, editado pelos autores.

é apresentada na Figura 3 e a composição dos seus indicadores é demonstrada a seguir.

Os indicadores foram agrupados em subíndices, considerando, para o subíndice QH, os indicadores referentes à análise da edificação e, para o subíndice $\mathrm{QC}$, a análise de seu contexto. $\mathrm{O}$ subíndice $\mathrm{QH}$ avaliou aspectos referentes à conservação das edificações, qualidade arquitetônica, observando diferenças nas características analisadas entre edificações verticalizadas e não verticalizadas; também foi avaliada a presença de jardins e pátios internos aos lotes, observando se eles se faziam presentes de forma mais significativa em lotes de edificações verticalizadas ou 
não verticalizadas, e quais os padrões construtivos mais privilegiados com relação à proximidade à orla marítima que margeia o bairro de Tambaú.

Com relação ao subíndice $Q C$, foram avaliados aspectos passíveis de interferência no contexto onde se encontram as edificações analisadas como: característica do tráfego de veículos local; presença de vegetação externa aos lotes e o estado de conservação dos passeios; afastamentos entre edificações e a interferência da projeção de sombras geradas a partir das edificações.

Foram utilizados os mesmos valores adotados por Scussel (2007) nos cálculos das matrizes de confronto (k), com o intuito de não interferir na composição e pontuações dos indicadores, fazendo, no entanto, as adaptações que se mostraram pertinentes devido à criação e inserção dos indicadores Ho e Cq. Com relação à inserção do indicador Ho, ela se mostrou pertinente por se estar analisando uma área da cidade de João Pessoa na qual a legislação de uso e ocupação do solo limita a altura das edificações próximas ao setor oceânico, interferindo na proximidade de edificações mais verticalizadas à área mencionada, com o intuito de preservação da paisagem. $\mathrm{O}$ indicador $\mathrm{Cq}$ foi inserido no QEH Adaptado em virtude do entendimento de que existe relação direta entre renda/ quantidade de veículos e quantidade de pessoas que ocupam determinado espaço. Observando que o bairro de Tambaú é de classe média/alta e que os seus moradores são detentores, em sua maioria, de veículos particulares, considerou-se, para a criação do indicador em questão, que diante de maior adensamento populacional, proporcionado pela verticalização, também ocorre maior concentração de veículos particulares.

O subíndice de Qualidade da Habitação $(\mathrm{QH})$ é função da composição de cinco indicadores:

$\mathbf{Q H}=\mathrm{f}(\mathrm{Hc}, \mathrm{Ht}, \mathrm{Ha}, \mathrm{Hp})$, na qual:

Hc $=$ Estado de conservação do edifício

$\mathrm{Ht}=$ Tipo edilício

Ha = Tipo arquitetônico do edifício

Hp = Qualidade e fruibilidade do espaço pertinente Ho $=$ Proximidade a orla marítima

O subíndice de Qualidade do Contexto da Habitação é composto, também, pela função de cinco indicadores:
$\mathbf{Q C}=\mathrm{f}(\mathrm{Cv}, \mathrm{Cr}, \mathrm{Cp}, \mathrm{Cg}, \mathrm{Ce})$, na qual:

$\mathrm{Cv}=$ Poluição e interferência do tráfego de veículos

$\mathrm{Cq}=$ Quantidade de vagas para veículos

$\mathrm{Cp}=$ Qualidade da paisagem perceptível desde

a habitação

$\mathrm{Cg}=$ Grau de privacidade

$\mathrm{Ce}=$ Exposição solar

Os valores encontrados com a aplicação das matrizes para o Subíndice de Qualidade da Habitação (QH) foram:

$\left(\mathrm{K}_{\mathrm{Hc}}=0,37 ; \mathrm{K}_{\mathrm{Ht}}=0,19 ; \mathrm{K}_{\mathrm{Ha}}=0,20 ; \mathrm{K}_{\mathrm{Hp}}=0,12 \mathrm{e}_{\mathrm{Ho}}=0,12\right)$, portanto:

$\mathbf{Q H}=0,37 \mathrm{Hc}+0,19 \mathrm{Ht}+0,20 \mathrm{Ha}+0,12 \mathrm{Hp}+0,12 \mathrm{Ho}$

Para o Subíndice de Qualidade do Contexto da Habitação (QC) foram adotados os valores:

$\left(\mathrm{K}_{\mathrm{Cv}}=0,29 ; \mathrm{K}_{\mathrm{Cq}}=0,23 ; \mathrm{K}_{\mathrm{Cp}}=0,22 ; \mathrm{K}_{\mathrm{Cg}}=0,12\right.$ e $\left._{\mathrm{Ce}}=0,14\right)$, portanto:

$\mathbf{Q C}=0,29 \mathrm{Cv}+0,23 \mathrm{Cq}+0,22 \mathrm{Cp}+0,12 \mathrm{Cg}+0,14 \mathrm{Ce}$

O cálculo final do Índice de Qualidade do Espaço da Habitação é composto por:

$\mathrm{QEH}=\left(\mathrm{K}_{\mathrm{QH}} \mathrm{QH}+\mathrm{K}_{\mathrm{QC}} \mathrm{QC}\right)$

Para $\mathrm{K}_{\mathrm{QH}}=0,60$ e $\mathrm{K}_{\mathrm{QC}}=0,40$

Portanto: QEH Adaptado $=0,60 \mathrm{QH}+0,40 \mathrm{QC}$

Cada indicador também foi avaliado a partir de critérios de atribuição de valores que variaram entre: bom/ótimo, com pontuação 1,00; insuficiente, com pontuação 0,50 ; ou péssimo, com pontuação de 0,05 . Portanto, cada indicador foi composto por duas ponderações: a que foi atribuída pela matriz de confronto de pares (k) e a que foi atribuída pelo pesquisador para cada lote avaliado.

De posse dos valores encontrados, esses são agrupados em 19 intervalos, e a escala de valores possíveis estabelecida varia entre 0,05 e 1,0; nela, a cada intervalo é atribuída uma cor específica, que Scussel (2007) estabeleceu numa gama de tons (dos vermelhos, para pontuações mais baixas, aos azuis, para as mais altas), obtendo-se, então, a possibilidade da geração de mapas de visualização de valores para cada índice. 


\section{Levantamento e análise da pesquisa de campo}

O levantamento nos quarteirões pesquisados foi realizado por indicador, seguindo a sequência $\mathrm{Hc}$, Ht, Ha, Hp, Ho, para avaliação do subíndice $\mathbf{Q H}$, e Cv, Cp, Cq, Cg e Ce para a avaliação do subíndice QC. O levantamento e a análise da pesquisa foram realizados por um único pesquisador, visando a manter a uniformidade no levantamento e nas avaliações.

$\mathrm{O}$ indicador $\mathrm{Hc}$ investigou o estado de conservação das edificações. Observou-se que, de forma geral, as edificações analisadas apresentavam estado satisfatório de conservação, sem presença de deteriorações em seus elementos aparentes e composições de fachada. 0 bairro de Tambaú encontra-se em uma área considerada "nobre" de João Pessoa, adequadamente dotada de infraestrutura, de serviços e de equipamentos públicos urbanos, com habitações de padrões arquitetônico e funcional compatíveis com sua localização na cidade, onde os moradores prezam por um padrão de qualidade construtiva, realçando o status social. A Figura 4 apresenta edificações verticalizadas do quarteirão $\mathrm{C}$.

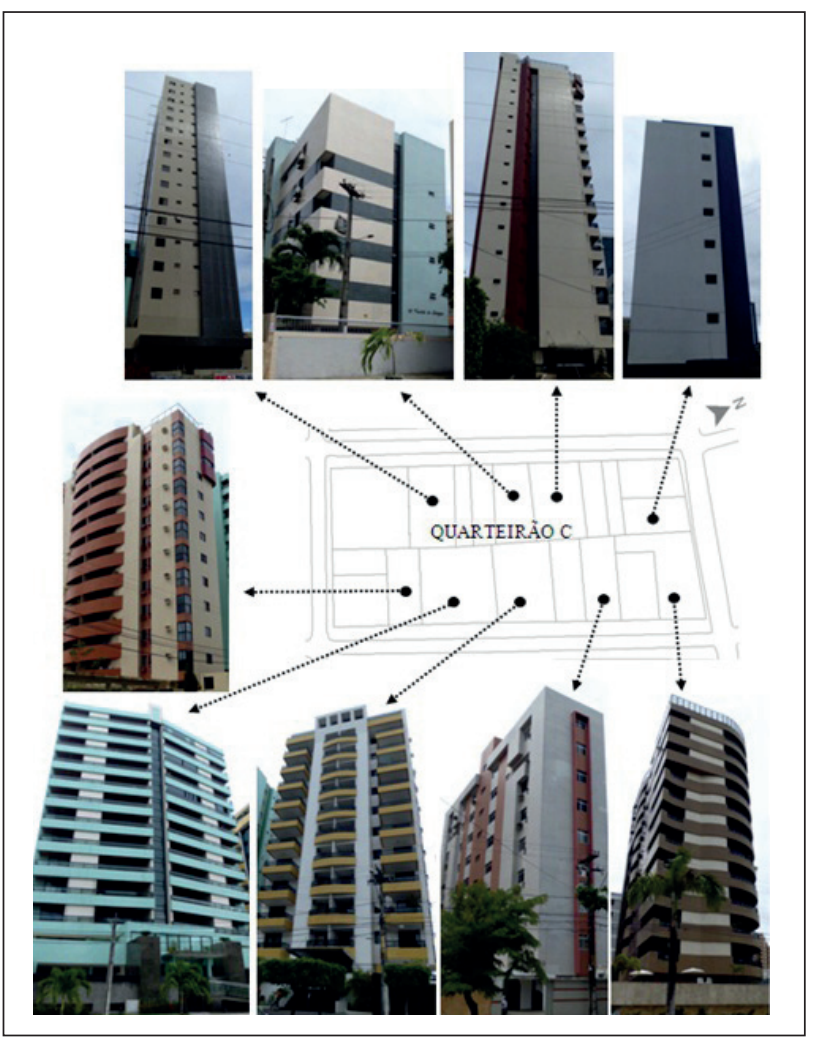

Figura 4 - Edificações verticalizadas presentes no quarteirão $C$ Fonte: SILVEIRA, 2011.
Com relação à análise do indicador em questão (Hc), não foram observadas diferenças que se mostrassem significativas, quanto ao grau de conservação entre edificações multifamiliares e unifamiliares, constatando-se que ambos os tipos de construção apresentaram-se, de forma geral, em satisfatório estado de conservação.

Para o preenchimento dos dados que conformaram o indicador $\mathrm{Ht}$, foi realizado o levantamento dos quarteirões pesquisados quanto à quantidade de pavimentos de suas edificações. A Figura 5 apresenta a diferença do padrão construtivo entre o quarteirão B, menos verticalizado, e o quarteirão C, mais verticalizado.
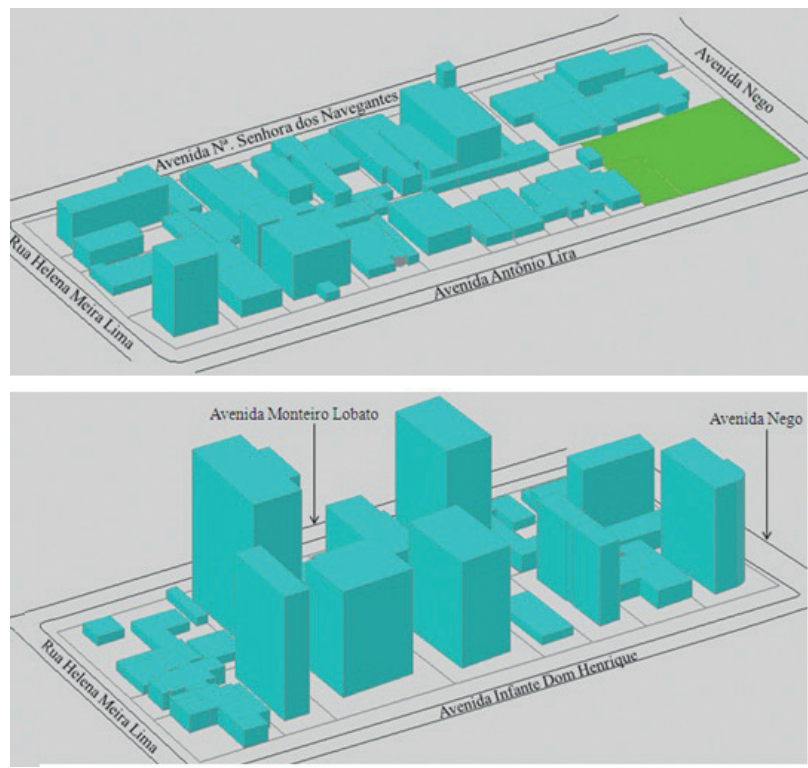

Figura 5 - Padrão construtivo nos quarteirões $B$ e $C$ Fonte: SILVEIRA, 2011.

Debates questionam sobre a partir de quantos pavimentos deve-se considerar uma construção como "verticalizada". A pesquisa considerou como horizontais as edificações unifamiliares, mesmo possuindo, além do pavimento térreo, um segundo pavimento. Foram consideradas verticalizadas as edificações denominadas multifamiliares.

A análise do indicador Ht mostrou-se importante, pois quanto maior é a altura de uma edificação, maior é a capacidade de adensamento populacional proporcionada pela multiplicação do solo. Também é maior a interferência da edificação na projeção de sombras, portanto, para esse indicador, 
foi adotado que quanto maior a edificação, maior seria sua interferência no entorno, inclusive em relação a questões microclimáticas. Receberam pontuações mais baixas, no preenchimento do banco de dados de avaliação das unidades, as edificações dos quarteirões $\mathrm{C}$ e $\mathrm{D}$, que concentram maior número de edificações multifamiliares verticalizadas e de maior altura.

Para a análise das edificações quanto à qualidade arquitetônica (Indicador Ha), foram observados aspectos que conferissem condições mínimas de qualidade na produção de um espaço habitado, como, por exemplo, o respeito à legislação urbanística e às condições físicas e geográficas do local de implantação. Aspectos como a harmonia com o contexto e a solução estética adotada também foram considerados para essa avaliação.

Nos quarteirões analisados não foi verificada a disseminação de sub-habitações. Algumas edificações, no entanto, encontravam-se em desarmonia com o contexto geral, sendo consideradas de má qualidade arquitetônica, com efeitos negativos sobre a paisagem. Pôde-se observar que essas construções foram resultado de adaptações realizadas, provavelmente, pelos próprios moradores dos lotes, visando à implantação de comércio e serviços ou simplesmente uma ampliação da área residencial já construída, mas que não levou em consideração um estudo arquitetônico apropriado e a legislação, quanto à questão dos recuos e contexto em que se inserem. Esses fatos destacam-se nos quarteirões A e B, menos verticalizados, dada a maior liberdade para modificações funcionais nas edificações unifamiliares.

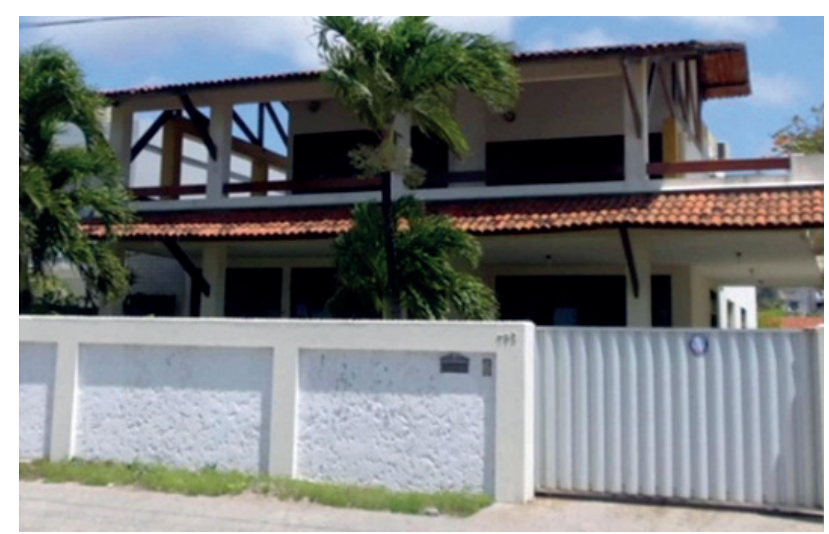

Figura 6 - Habitações unifamiliares (quarteirão A) Fonte: SILVEIRA, 2011.
Observou-se que as edificações verticalizadas mantiveram um padrão de qualidade arquitetônico, sendo construções, em geral, resultantes de projetos elaborados por profissionais. Foram preservados padrões de simplicidade e limpeza das fachadas, com aberturas arejadas, garantindo a entrada de ventilação e iluminação. A maioria das edificações possui amplas varandas voltadas para a orientação da ventilação predominante local (ventilação na direção sudeste com variantes de nordeste), direcionadas para o sol nascente. No entanto, as edificações verticalizadas apresentaram padrão semelhante de solução estética, com suas fachadas com janelas envidraçadas e a alvenaria recoberta por pastilhas cerâmicas.

Salienta-se que, do ponto de vista estético, as edificações residenciais unifamiliares se mostraram com soluções mais criativas, com relação ao jogo de volumes e interação entre materiais. De acordo com Holanda (1976), em suas considerações ainda atuais, a arquitetura de qualidade para o Nordeste deve tirar partido de varandas, sombreamentos, adoção de artifícios de adaptação climática, circulação de ar, luz e preocupação com arremates construtivos como beirais. A maioria das residências unifamiliares analisadas, como as apresentadas na Figura 6, foi considerada de qualidade arquitetônica diante da avaliação dos elementos citados.

Com relação à presença de jardins e pátios, análise que compõe o indicador $\mathrm{Hp}$, foi observado que a maioria das edificações multifamiliares verticalizadas não possuía jardins ou pátios significativos com vegetação de médio e grande porte em sua área de lazer interna. Muitas apresentavam apenas plantas em jarros ou uma pequena área destinada a gramado e

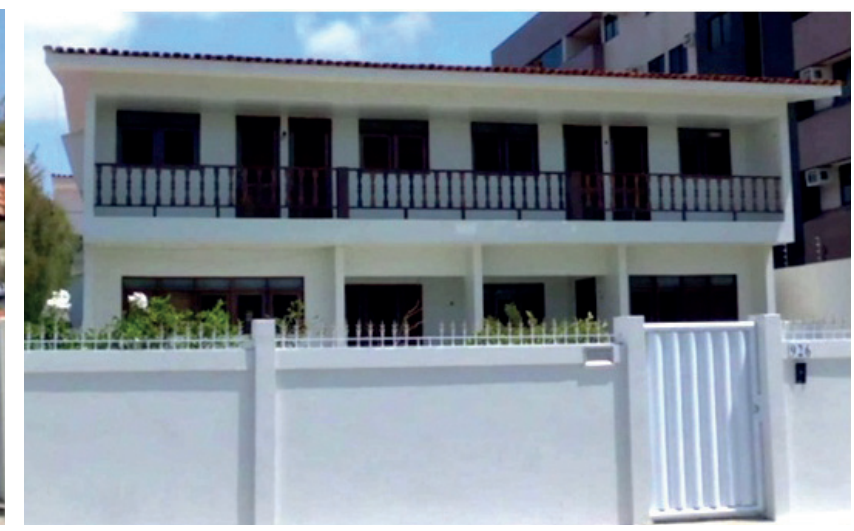


vegetação rasteira, como mostra a primeira imagem da Figura 7. Em outras edificações multifamiliares, observou-se que o único jardim a que se podia fazer referência era a área gramada, com alguma vegetação, de pequeno e médio porte, que se encontrava contornando o muro da fachada frontal e das guaritas das edificações. No interior de alguns lotes das residências unifamiliares, observou-se a presença de vegetação, com árvores de grande e médio porte, como mostra a segunda imagem da Figura 7, diferentemente das edificações multifamiliares analisadas.

A análise dos lotes para cada indicador seguiu a valoração adotada por Scussel (2007). Para o indicador Hp, por exemplo, as valorações estão demonstradas no Quadro 1.
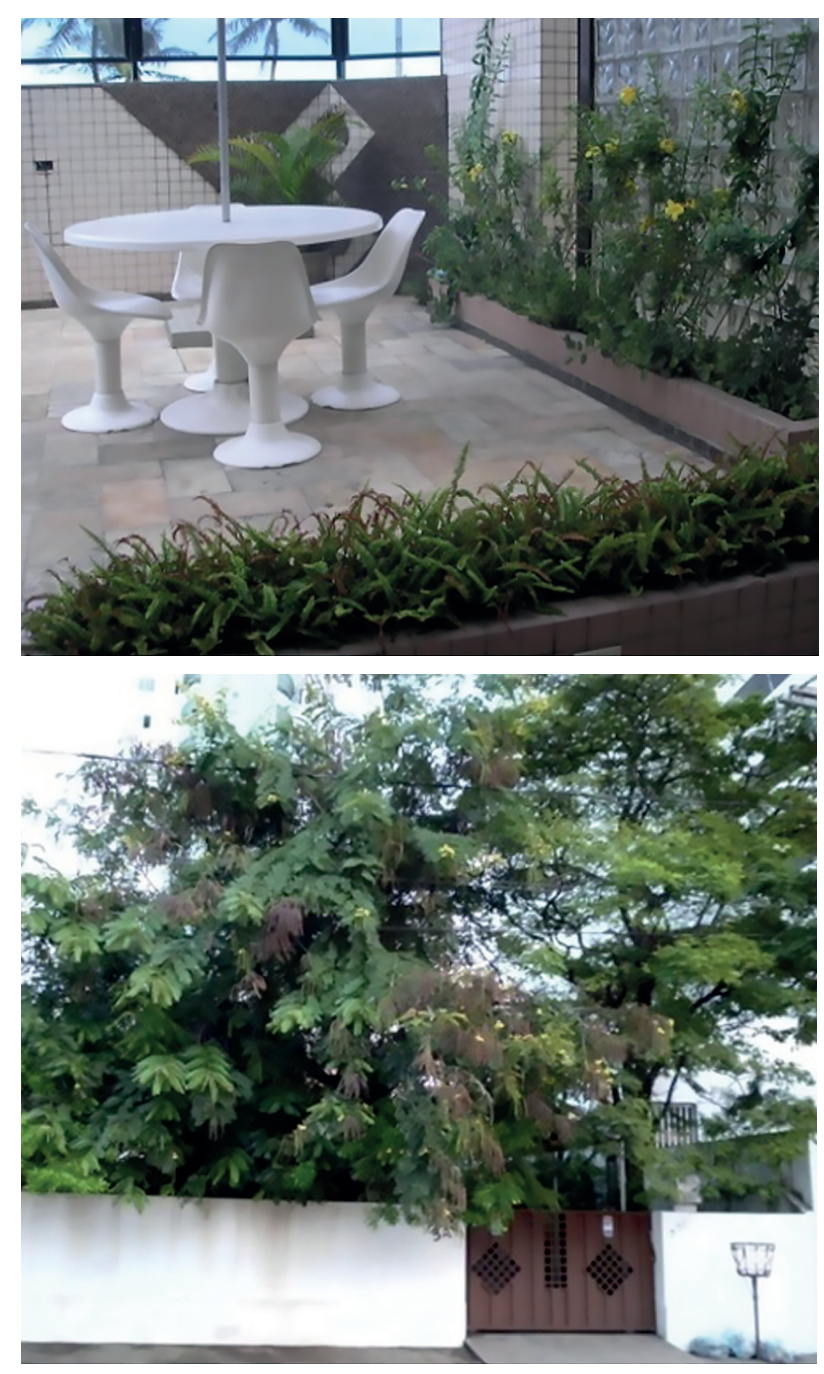

Figura 7 - Vegetação da área de lazer de edificação multifamiliar (quarteirão A) e vegetação de edificaçã̃o unifamiliar (quarteirão D) Fonte: SILVEIRA, 2011.
Quadro 1 - Valoração referente à presença de jardins e pátios internos aos lotes (indicador $\mathrm{Hp}$ )

\begin{tabular}{lll}
\hline Indicador & Valor & Critério de atribuição do valor \\
\hline Hp & Bom/ótimo & Presença de jardins e pátios de elevada qualidade. \\
& Insuficiente & $\begin{array}{l}\text { Presença de jardins e pátios de qualidade modesta, } \\
\text { mas desfrutáveis. }\end{array}$ \\
& Péssimo & $\begin{array}{l}\text { Ausência de verde, pátios não desfrutáveis, a não } \\
\text { ser para uso de serviço. }\end{array}$ \\
\hline
\end{tabular}

Fonte: SCUSSEL, 2007.

Na análise do indicador Ho, receberam maior pontuação os quarteirões (e respectivos lotes) que se encontraram mais próximos à orla marítima que margeia o bairro de Tambaú, tendo em vista que esse elemento foi considerado como um atrativo paisagístico e de lazer para os moradores do local que não possuíam outras áreas distribuídas de maneira uniforme, com relação ao espaço do bairro, destinadas à caminhada, prática de esportes, contemplação e convívio social.

Villaça (2001) explica que os setores oceânicos, com seus atrativos do sítio natural, constituem importante fator de atração da expansão e adensamento urbano. A localização física das edificações, de acordo com o autor, é um fator importante dentro da malha urbana. A proximidade a essa localização significa proximidade a uma paisagem contemplativa, dotada de ventilação, com área destinada à prática de esportes, calçadas para caminhada e corrida e ciclovia, como no caso da localização dos quarteirões A e B. À medida que a localização se distancia, em direção ao interior do continente, também vai se distanciando das amenidades e benefícios mencionados, além de deixar as habitações mais expostas ao sol poente, uma insolação indesejável. Nessa área também se encontra um setor habitacional precário com alocação de um assentamento irregular assemelhado a uma favela. Os quarteirões $C$ e $D$, mais distantes da orla, são também os quarteirões mais verticalizados da pesquisa, pois a legislação de uso e ocupação do solo atuante na área limita a altura das edificações mais próximas à beira mar, com um gabarito de altura crescente à medida que se direciona ao interior do continente.

Para obter os resultados do indicador $\mathrm{Cv}$, referente à análise do tráfego de veículos nas vias que 
margeiam os quarteirões pesquisados, observou-se o nível dessa movimentação em horários de maior intensidade de circulação. Foi possível verificar que as vias próximas à orla marítima possuíram os maiores volumes de tráfego de veículos de Tambaú, fato que pode ser explicado, dentre outras razões, por essas vias fazerem fronteira com o setor oceânico atrativo paisagístico local - além de serem circundadas por comércio e serviços, com edifícios empresariais, pousadas e hotéis, polos atrativos tanto para a população local como para os turistas. Essas avenidas são as mais largas de Tambaú, além de serem asfaltadas, servindo de vias de passagem para bairros vizinhos. É possível observar, na Figura 8, a demanda permanente por vagas para veículos, em uma das laterais da Avenida Almirante Tamandaré, que faz fronteira com a orla de Tambaú.

Vias de circulação de automóveis localizadas na direção do interior do bairro possuem larguras menores, além de não apresentarem, nos espaços adjacentes, atrativos paisagísticos e de lazer, comércio e serviços diversificados. 0 movimento dos automóveis nas vias citadas pode ser explicado, sobretudo, pela presença das edificações residenciais verticalizadas, a maioria com mais de dez pavimentos, abrangendo uma densidade populacional elevada e aumentando a demanda por estacionamentos para os veículos dos moradores locais e visitantes.

Para a obtenção dos dados que conformaram o indicador $\mathrm{Cq}$, que versa sobre a quantidade de vagas de veículos por lote, foram contabilizadas as quantidades de vagas oferecidas nas edificações verticalizadas. Para análise desse indicador, foi considerado para as residências unifamiliares um parâmetro máximo de três veículos por lote.

Vasconcellos (2001) explica que existe relação entre renda e uso de transporte individual, esclarecendo que se vive em um sistema de agregação de valores fundado no consumo e na imagem, portanto, se uma edificação verticalizada oferece três vagas de garagem, por apartamento, em um bairro de classe média/alta, torna-se convidativa para o morador a ocupação de todas essas vagas. Observou-se que algumas edificações residenciais verticalizadas chegavam a oferecer até quatro vagas de garagem por unidade habitacional nos quarteirões pesquisados. Os quarteirões $\mathrm{C}$ e $\mathrm{D}$, caracterizados pela maior presença de edificações verticalizadas receberam menores pontuações, com relação ao indicador em questão, pois também concentraram maior quantidade de veículos por área, quando comparados aos quarteirões A e B, menos verticalizados e com menor concentração de veículos por área.

No levantamento do indicador $\mathrm{Cp}$, que analisou a qualidade da paisagem perceptível desde a habitação, obtiveram maior pontuação os lotes que apresentaram os passeios adjacentes em estado satisfatório de conservação e com presença de vegetação de grande porte, por esses elementos valorizarem o contexto externo edificado e não edificado, por intermédio da

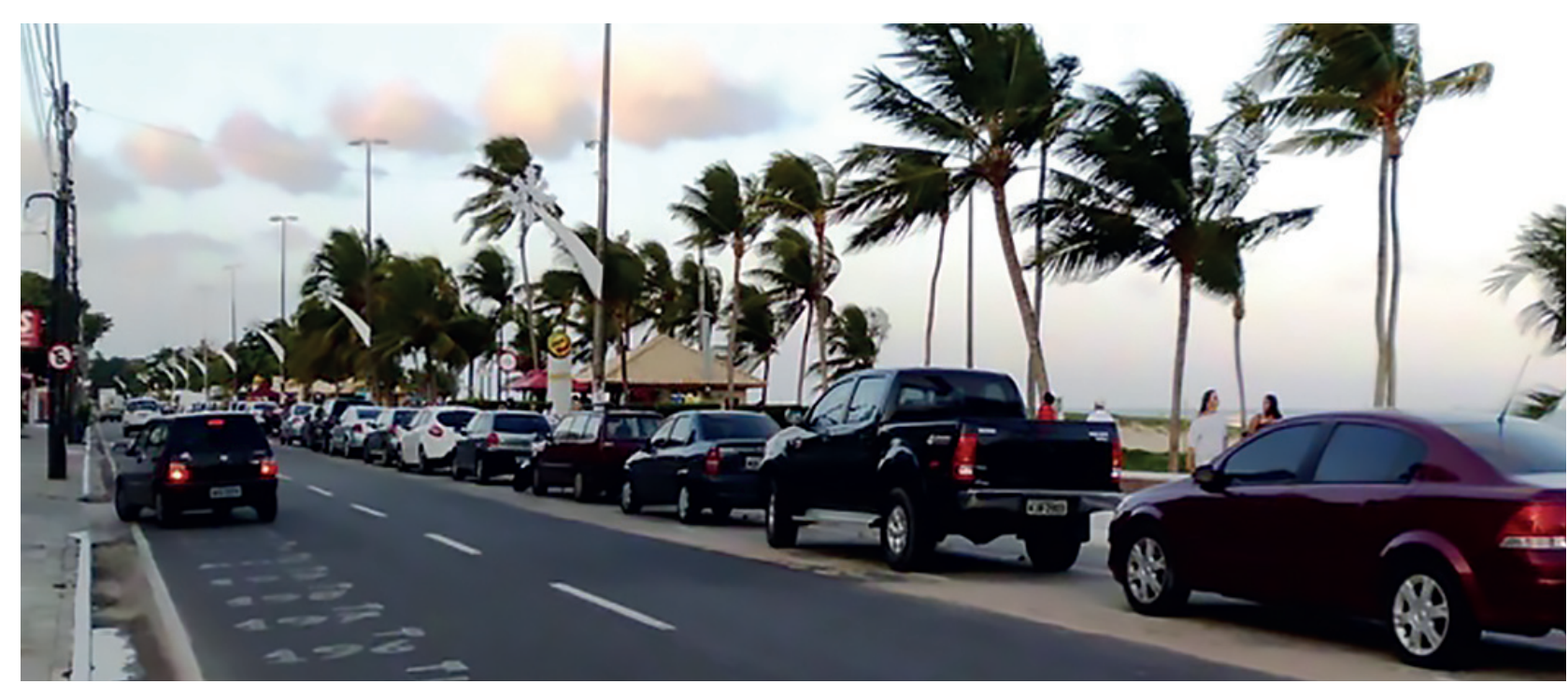

Figura 8 - Avenida Almirante Tamandaré na orla maríima do bairro de Tambaú Fonte: SILVEIRA, 2011. 
cobertura vegetal e composição dos espaços adjacentes diretos componentes da microacessibilidade calçadas. Receberam menor pontuação as calçadas que se encontraram deterioradas e sem presença de vegetação de grande/médio porte, como mostra a segunda imagem da Figura 9.
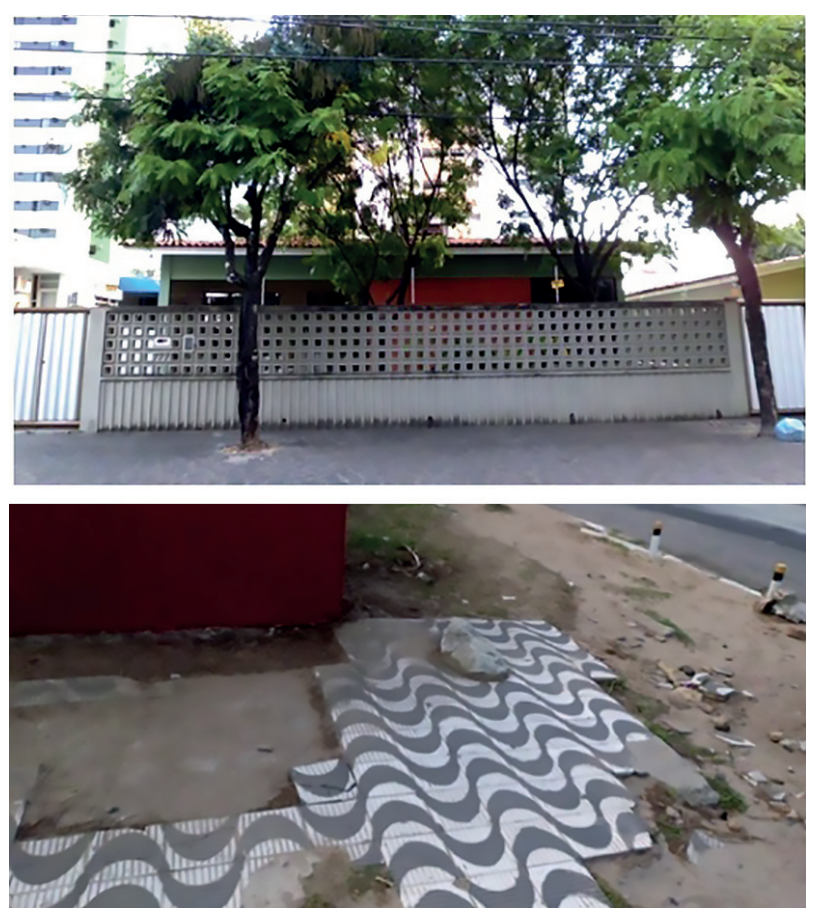

Figura 9 - Áreas de passeios públicos em Tambaú Fonte: SILVEIRA, 2011.

Nota: À esquerda, passeio em estado satisfatório de conservação e com presença de vegetação; à direita, passeio em estado precário de conservação e sem presença de vegetação (quarteirões D e B).

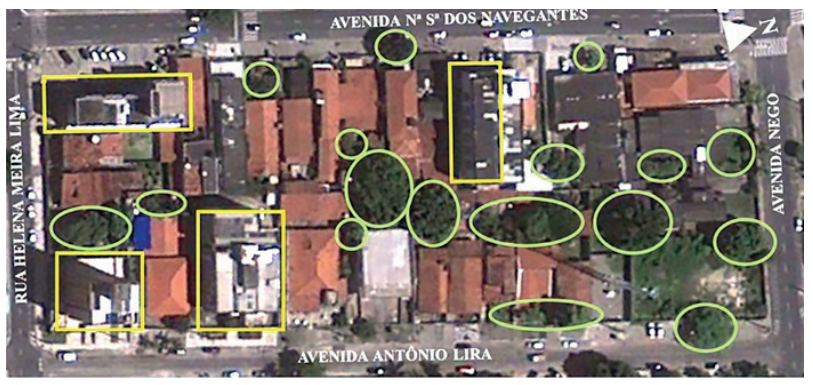

Legenda

$\square$ Edificacẫos Verticais $\quad \bigcirc$ Áreas Verdes

Figura 10 - Vista aérea do quarteirão B, com delimitação de áreas verdes e edificaç̃oes verticalizadas

Fonte: Imagem extraída de Google Earth (2010), editada pelos autores.
Observou-se nos quarteirões mais verticalizados (C e D), além da menor presença de vegetação em sua área total, que o verde se encontrava presente de forma mais significativa contornando as quadras, não sendo tão presente em seu interior, como é possível visualizar nas Figuras 10 e 11.0 quarteirão $\mathrm{B}$, menos verticalizado, possui presença maior de vegetação, se comparado ao quarteirão $\mathrm{D}$, mais verticalizado.

Observou-se que as calçadas em melhor estado de conservação, de forma geral, foram aquelas das edificações multifamiliares, o que pode ser explicado pelo fato desse tipo de construção ter muitas famílias residentes, na qual despesas com manutenção são obrigatórias para todos os condôminos, incluindo limpeza e conservação de áreas como os passeios. Nas edificações unifamiliares não há essa corresponsabilidade que obriga os moradores a preservar de forma disciplinar os passeios. No entanto, observou-se que essas áreas públicas adjacentes às edificações multifamiliares não possuíam vegetação de médio e grande porte de forma significativa, pois se mostraram mais presentes nas calçadas ligadas às edificações unifamiliares. Carvalho, Corbella e Dias (2007) explicam que a urbanização crescente nos bairros litorâneos da cidade de João Pessoa, incluindo o bairro de Tambaú, tem provocado a redução da cobertura vegetal e das áreas de solo permeável.

Para o indicador $\mathrm{Cg}$, que se refere ao grau de privacidade, levando em conta os afastamentos entre as edificações, foram considerados certos preceitos

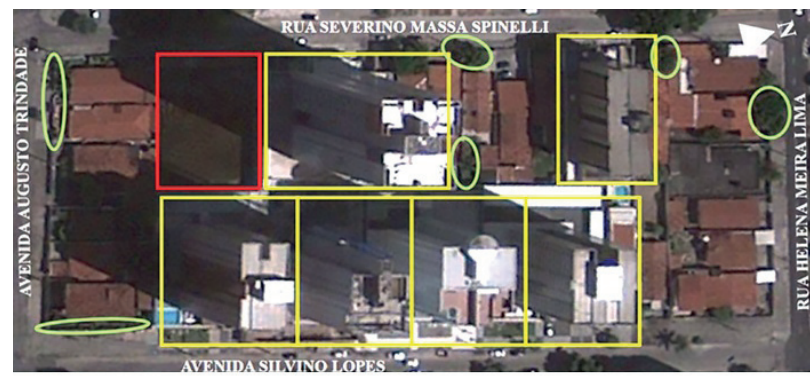

Legenda

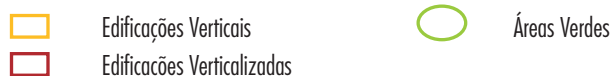

Figura 11 - Vista aérea do quarteirãa D com delimitação de áreas verdes, edificações verticalizadas e lotes que passaram por inserç̦̃o de edificacação verticalizada Fonte: Imagem extraída de Google Earth (2010), editada pelos autores. 
ditos "modernistas", como também foram feitas análises dos recuos estabelecidos pela legislação de uso e ocupação do solo para a zona de Tambaú. Gropius (1977) afirmava que, quanto mais altos os edifícios, maiores deveriam ser os afastamentos entre eles. Dentre os afastamentos, haveria a possibilidade da criação de parques e jardins. Deve-se entender que os recuos prediais têm por objetivo garantir adequadas condições de ventilação e iluminação e evitar que as edificações estejam muito próximas umas das outras, garantindo a privacidade e propiciando a recreação, além de manter a permeabilidade do solo. Em Tambaú, não se observaram, entre as edificações pesquisadas, afastamentos consideráveis, se forem ponderadas, por exemplo, as distâncias propostas por urbanistas ditos modernos como Le Corbusier (1984), que defendia a construção de edificações verticalizadas a grandes distâncias (200 m a $300 \mathrm{~m}$ ) umas das outras. Deve-se ponderar, no entanto, que a aferição de afastamentos e recuos varia de região para região e que a maneira como é empregada depende da época em que se vive, da legislação urbanística local e de como é avaliada. Mais ainda: a legislação está sob a influência do poder econômico e dos interesses dos agentes promotores imobiliários; daí, esses interesses também têm implicações sobre o modelo de ocupação e de uso da terra urbana. Assim, esses fatos são resultantes da interação de ações e projetos e do jogo de interesses dos atores que interagem no espaço urbano.

A Figura 12 apresenta os afastamentos entre edificações verticalizadas do quarteirão D, mostrando que esses não chegam a 20 m de distância.

Para a análise da iluminação solar direta, nos quarteirões A, B, C e D, e atribuição de valores para o indicador Ce, foram realizados levantamentos de projeção de sombras das edificações, nos quais foi possível observar que edificações menos verticalizadas, como as do quarteirão $\mathrm{A}$, não projetavam suas sombras de forma significativa nas edificações vizinhas, o que não ocorreu com as edificações verticalizadas, por exemplo, do quarteirão $\mathrm{D}$, como mostra a Figura 13.

Observou-se que nos quarteirões mais verticalizados (C e D), nos meses de junho e julho, às 8h30, as edificações mais altas projetavam suas sombras mais significativas nas edificações vizinhas. Nos meses de janeiro e fevereiro, às $15 \mathrm{~h}$, as sombras projetadas encontravam-se direcionadas para o sentido

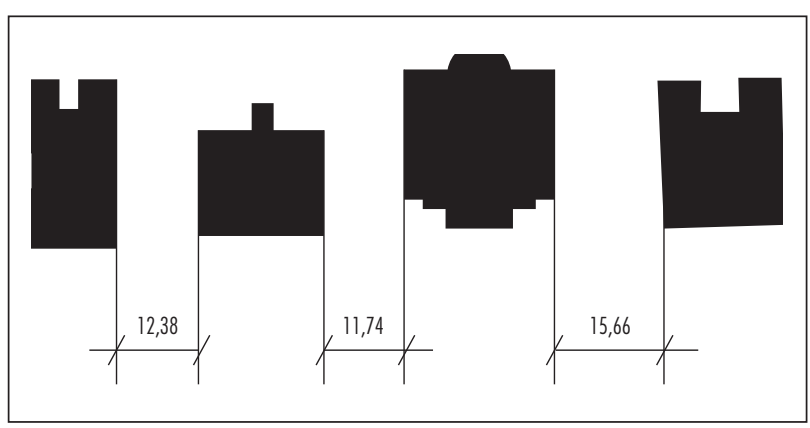

Figura 12 - Edificaç̃ões verticalizadas do quarteirão D e a distância entre elas Fonte: SILVEIRA, 2011.
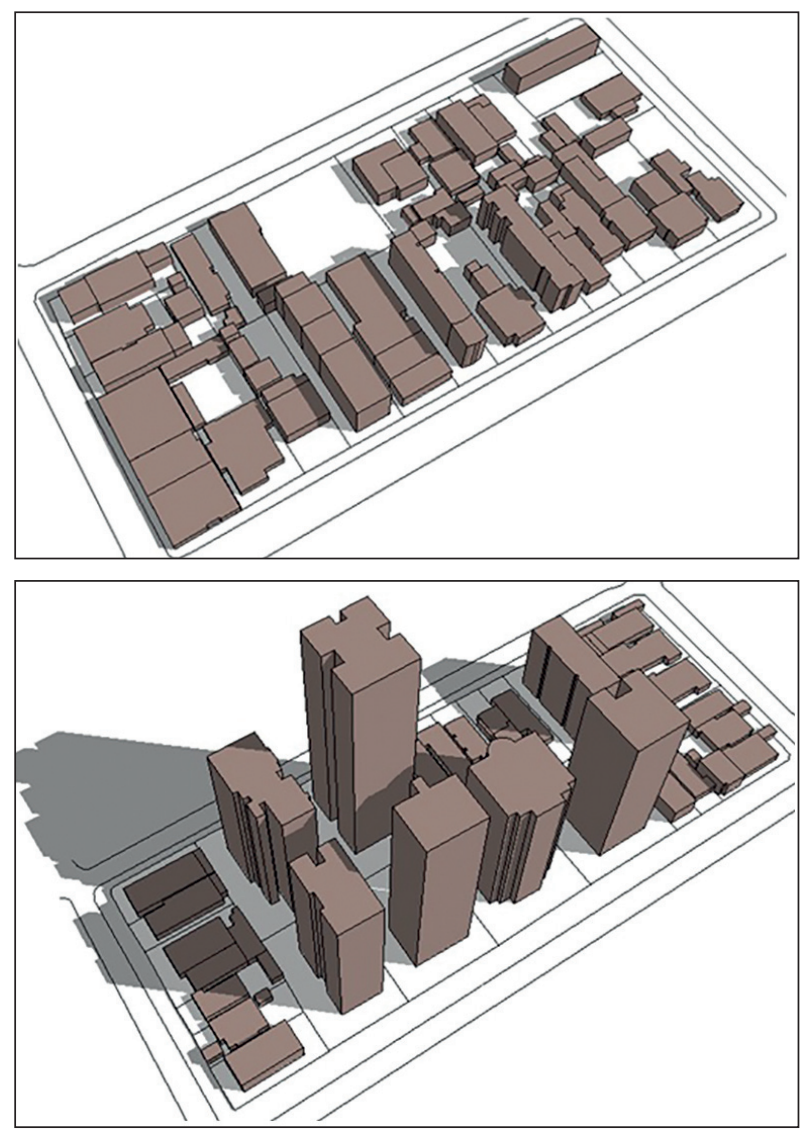

Figura 13 - Simulaç̦ão de sombreamento, jun./jul., 8 30 (quarteirões A e D) Fonte: SILVEIRA, 2011.

dos passeios e vias de circulação, o que pode ser considerado, em determinadas situações, um aspecto positivo, como, por exemplo, na proteção desses passeios e vias em horários de intensa e indesejada iluminação solar direta; mas também pode ser visto como aspecto negativo, por exemplo, por aumentar a velocidade dos ventos, que podem se tornar incômodos, como também por projetar sombras para 
áreas de residências na qual se deseja a presença da insolação, como em áreas de lazer com piscina e jardins, além das áreas de serviços. É importante observar, também, que os raios solares contribuem para promover a higienização de ambientes e objetos, em locais onde se façam presentes, eliminando microorganismos.

\section{Cálculo do índice de Qualidade do Espaço da Habitação (QEH) adaptado}

De posse dos dados do levantamento e posterior análise, pôde-se passar para a fase de preenchimento do banco de dados dos cálculos dos índices e subíndices do QEH adaptado. Os dados obtidos foram distribuídos em tabelas, à semelhança da Tabela 2 , referente aos dados compilados de alguns lotes do quarteirão B, escolhido para exemplificação.

Dos resultados obtidos com os cálculos das tabelas mencionadas, passou-se à etapa de elaboração dos mapas de valores. As Figuras 14 e 15 apresentam o mapeamento dos quarteirões A, B, C e D para a indicação dos valores do Índice de Qualidade do Espaço da Habitação - QEH adaptado.
Observando os resultados dos mapas de colorização, verificou-se que, de modo geral, os quarteirões A e B apresentaram índices ligeiramente superiores aos dos quarteirões $\mathrm{C}$ e $\mathrm{D}$, em termos da qualidade do espaço residencial. É importante observar ainda que o índice adotado faz uma síntese de indicadores agregados em subíndices, mostrando-se importante a análise dos indicadores de forma desagregada para que seja possível a identificação de quais aspectos concorrem mais significativamente para o resultado (SCUSSEL; SATTER, 2010; SOCCO et al., 2002).

Um dos indicadores responsáveis pelas menores pontuações para as edificações pesquisadas, no subíndice $\mathrm{QH}$, foi o indicador $\mathrm{Hp}$, referente à presença de jardins e pátios internos dos lotes analisados. Foi observado que a vegetação se fez presente de maneira mais significativa nos lotes das edificações unifamiliares. As edificações multifamiliares costumam destinar suas áreas comuns a espaços, em geral, impermeabilizados, destinados às vagas de garagem, e lazer, como áreas para piscina e quadras esportivas.

$\mathrm{Na}$ análise do indicador Ho, também receberam pontuações mais baixas as edificações dos

Tabela 2 - Cálculo do Índice QEH adaptado para lotes do quarteirão B

\begin{tabular}{|c|c|c|c|c|c|c|c|c|c|c|c|c|c|}
\hline \multicolumn{14}{|c|}{ QEH Adaptado } \\
\hline \multirow{2}{*}{$\begin{array}{l}\text { Identificaçãóo } \\
\text { Lotes } \\
\text { Quarteirão B }\end{array}$} & \multicolumn{5}{|c|}{$\mathrm{QH}$} & \multicolumn{7}{|c|}{$Q C$} & \multirow[t]{2}{*}{ QEH } \\
\hline & KQH & $x$ & $\mathrm{QH}$ & $=$ & TOTAL & + & $K Q C$ & $x$ & $Q C$ & $=$ & TOTAL & $=$ & \\
\hline B 521 & 0,6 & $x$ & 0,886 & $=$ & 0,531 & + & 0,4 & $x$ & 0,417 & $=$ & 0,166 & $=$ & 0,697 \\
\hline B 184 & 0,6 & $x$ & 0,786 & $=$ & 0,471 & + & 0,4 & $x$ & 0,685 & $=$ & 0,274 & $=$ & 0,745 \\
\hline B 172 & 0,6 & $x$ & 1 & $=$ & 0,6 & + & 0,4 & $x$ & 0,745 & $=$ & 0,298 & $=$ & 0,898 \\
\hline B 440 & 0,6 & $x$ & 0,791 & $=$ & 0,474 & + & 0,4 & $x$ & 0,526 & $=$ & 0,21 & $=$ & 0,684 \\
\hline B 420b & 0,6 & $x$ & 1 & $=$ & 0,6 & + & 0,4 & $x$ & 0,795 & $=$ & 0,318 & $=$ & 0,918 \\
\hline B 400b & 0,6 & $x$ & 0,606 & $=$ & 0,363 & + & 0,4 & $x$ & 0,636 & $=$ & 0,254 & $=$ & 0,617 \\
\hline В 380 & 0,6 & $x$ & 0,94 & $=$ & 0,564 & + & 0,4 & $x$ & 0,586 & $=$ & 0,234 & $=$ & 0,798 \\
\hline B 356 & 0,6 & $x$ & 1 & $=$ & 0,6 & + & 0,4 & $x$ & 0,855 & $=$ & 0,342 & $=$ & 0,942 \\
\hline B 338 & 0,6 & $x$ & 0,94 & $=$ & 0,564 & + & 0,4 & $x$ & 0,685 & $=$ & 0,274 & $=$ & 0,838 \\
\hline B 334 & 0,6 & $x$ & 0,94 & $=$ & 0,564 & + & 0,4 & $x$ & 0,586 & $=$ & 0,234 & $=$ & 0,798 \\
\hline B 322 & 0,6 & $x$ & 0,815 & $=$ & 0,489 & + & 0,4 & $x$ & 0,646 & $=$ & 0,258 & $=$ & 0,747 \\
\hline В 314 & 0,6 & $x$ & 1 & $=$ & 0,6 & + & 0,4 & $x$ & 0,685 & $=$ & 0,274 & $=$ & 0,874 \\
\hline В 304 & 0,6 & $x$ & 1 & $=$ & 0,6 & & 0,4 & $x$ & 0,685 & $=$ & 0,274 & $=$ & 0,874 \\
\hline
\end{tabular}

Fonte: SILVEIRA, 2011. 
quarteirões C e D - mais verticalizados - , por se localizarem mais afastadas da orla marítima que margeia o bairro de Tambaú. A proximidade ao oceano foi considerada indicativo de qualidade residencial urbana.

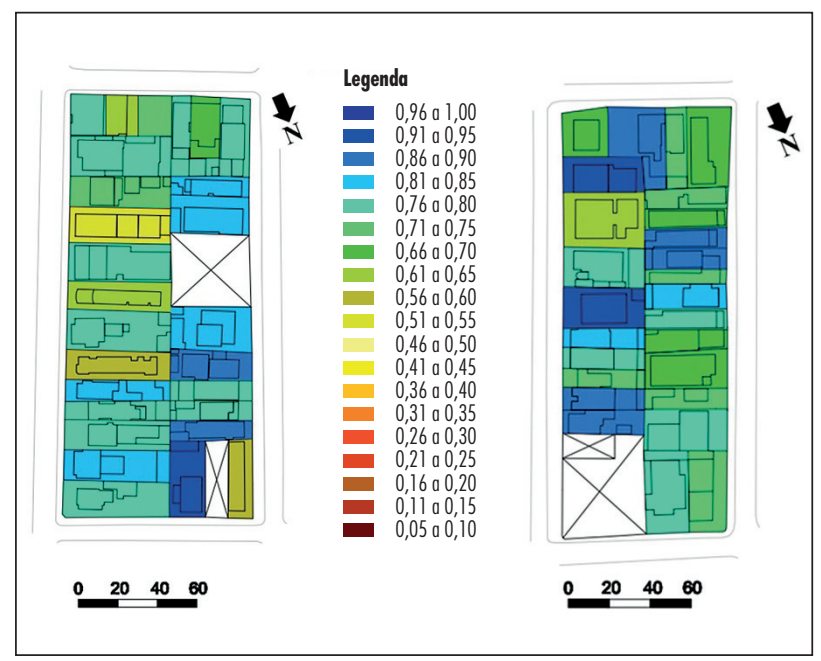

Figura 14 - Mapa QEH (quarteirões A e B)

Fonte: SILVEIRA, 2011.

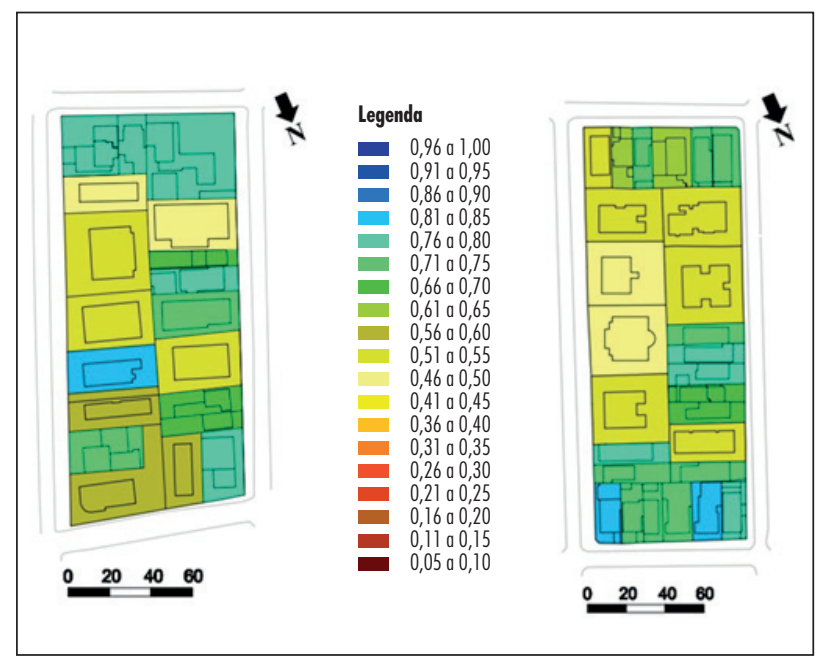

Figura 15 - Mapa QEH (quarteirões ( e D)

Fonte: SILVEIRA, 2011.

Avaliando comparativamente os subíndices QH e QC, observou-se que o subíndice QC recebeu pontuações menores. Esse fato pode ser explicado pelas pontuações mais baixas atribuídas aos indicadores Cv e Cp. $\mathrm{O}$ indicador Cv mostrou como o aumento da quantidade de veículos em circulação podeinterferirnaqualidaderesidencialdeumlocal. No entanto, deve-se considerar que a quantidade de veículos circulando em um local não está relacionada unicamente com a presença da verticalização e o adensamento populacional da área. Outros fatores podem interferir para essa maior demanda, como a presença de comércio e serviços e a utilização das vias para passagem a outros locais.

Com relação à análise do indicador $\mathrm{Cq}$, os quarteirões $\mathrm{C}$ e D receberam menores pontuações por concentrarem maior número de edificações verticalizadas que os quarteirões A e B. Essa maior concentração de edificações verticalizadas aumenta o número de residentes em determinado local, aumentando, consequentemente, o número de veículos.

$\mathrm{O}$ indicador $\mathrm{Cp}$ também influiu com pontuações baixas para a conformação do subíndice QC. Foi observado que as calçadas, de forma geral, não se encontravam em condições satisfatórias, ou por se apresentarem em estado precário de conservação ou por não possuírem em seus passeios vegetação de médio e grande porte.

$O$ indicador Ce também interferiu na pontuação do subíndice QC, baixando a pontuação dos quarteirões mais verticalizados (C e D), devido a interferência da projeção da sombra das edificações desses quarteirões na iluminação solar direta das edificações do seu entorno.

\section{Considerações finais}

Retomando as intenções inicialmente colocadas, acredita-se ter oferecido contribuição à avaliação do impacto da verticalização na qualidade do espaço residencial, utilizando a ferramenta QER, sob os aspectos da Qualidade do Espaço da Habitação (QEH adaptado).

Como uma de suas contribuições, a pesquisa captura avaliação específica de características qualificadoras do espaço e do meio ambiente, diferenciadas das investigações anteriores, nas quais os atributos são estabelecidos pelos processos socioespaciais urbanos, com impactos importantes nas localizações da cidade.

A atribuição de ponderação no trabalho implicou a consideração de juízo de valor, na qual a 
flexibilidade da estrutura analítica do QER, aqui destacada, propicia a adequação do método a variadas realidades,fatorelevanteaoavançocientíficodotema. Ao mesmo tempo, constitui-se em subsídio preditivo a possíveis rearranjos na estrutura física ou em projetos existentes, podendo, inclusive, prestar-se também como elemento de introdução da população na gestão do bairro.

Destaca-se a sensibilidade dos subíndices QH e $\mathrm{QC}$, face à intensidade e velocidade das transformações em curso e da verticalização urbana, podendo alterar negativamente os indicadores que os compõem, diretamente relacionados às lógicas funcionais e práticas socioespaciais da dinâmica da cidade, a exemplo da ocupação e uso do solo urbano, transportes, relações sociais e consumo.

0 processo de verticalização acentuado tem confrontado combinações e conflitos urbanos, entre os atores que produzem e reproduzem o espaço intraurbano. Assim, é o resultado da interação de ações e projetos e do jogo de interesses dos atores que interagem no espaço da cidade.

$O$ Índice QEH adaptado pode contribuir à leitura de diferentes indicadores, permitindo análise de quais fatores podem interferir de forma mais significativa na avaliação da relação entre verticalização e qualidade no espaço residencial, oferecendo-se aqui um estudo adaptado, em uma região diferente das pesquisas anteriores desenvolvidas por Socco et al. (2002) e Scussel (2007).

A aferição dos indicadores analisados atesta que a verticalização pode interferir na área onde esse processo se insere, como, por exemplo, por meio do incremento do tráfego de veículos, mesmo sendo sabido que a quantidade de veículos circulando em determinado espaço não apresenta relação unicamente com a verticalização, mas essa tem influência sobre a área onde se insere, pois a verticalização, no país, apresenta-se como um processo característico de setores ocupados e adensados por populações de classes média e alta, detentoras de veículos particulares.

Ao interferir no estabelecimento de novas relações de luz e sombra no espaço, a verticalização também pode provocar sombreamentos de variados níveis nas áreas ao seu redor, pois quanto maior a altura das edificações, maior pode ser a área de sombra projetada, influindo no microclima e na paisagem urbana.
O processo histórico e a verticalização também podem interferir no reordenamento e redimensionamento de áreas livres e vegetadas, modificando a paisagem, como se pode observar nas Figuras 10 e 11, compondo relação importante no jogo de interesses da cidade. É possível observar que, na cidade de João Pessoa, os bairros onde se evidencia maior ocorrência de áreas verdes públicas representativas coincidem com os espaços mais centrais, nos quais historicamente as áreas verdes eram valorizadas e utilizadas, inclusive com a preocupação de estabelecer continuidade entre elas. De modo geral, outras áreas de ocupação permanente e adensamento, como Tambaú, assistiram, mais recentemente, situação em que os espaços públicos passaram a gerar insegurança às populações de média e alta renda, que preferem os espaços fechados de condomínios verticais e/ou horizontais, e de lazer, influindo, juntamente com a verticalização, nas novas escalas e percepção do ambiente construído urbano. Mais uma vez, considere-se que a especulação imobiliária, interessada em transformar solo em terra-localização rentável, também produz efeitos no quadro apresentado, negligenciando as áreas livres públicas, em loteamentos e bairros da cidade.

Questões como as que foram mencionadas têm promovido transformações no bairro de Tambaú, colocando em dúvida se o padrão construtivo que vem sendo adotado faz da área "um bom lugar para morar", segundo termos adotados por Scussel (2007).

A verticalização se apresenta, portanto, como um tema importante a ser abordado, por esse processo se fazer cada vez mais presente nas médias e grandes cidades do país e interferir em sua dinâmica. Esse modelo de solução adotada vem definindo a nova forma de morar nas malhas urbanas do Brasil. No espaço urbano cada vez mais valorizado, a verticalização oferece a possibilidade especulativa de multiplicação do solo. No entanto, além de trazer aparentes benefícios, como a possibilidade de maior proximidade a comércio e serviços, diminuindo o tempo com deslocamentos, esse tipo de solução deve ser empregado de forma disciplinada, considerando os variados aspectos da cidade como um todo, de modo sistêmico.

A verticalização urbana, nos padrões que vêm sendo adotados, deve servir de exemplo para a reflexão sobre as diversas dimensões que envolvem esse fenômeno, os limites ao processo de uso e 
ocupação da terra urbana, e a diversidade, contrastes e relevância da escala urbana e humana para a qualidade de vida (LAPA, 2011). Deve-se refletir sobre o percurso que a cidade vem adotando e se essa é a melhor solução a ser seguida, inclusive no âmbito do debate sobre cidades compactas versus cidades difusas e nucleadas, quando se trata da busca por melhor qualidade do espaço residencial urbano.

A verticalização acentuada foi adotada como uma das formas de ocupação e aproveitamento da terra urbana e o que se observa, muitas vezes, é um "empilhamento" de edificações verticalizadas e, consequentemente, um "empilhamento" humano. Esse tipo de ocupação do solo verticalizado, sem um planejamento estrutural e global da cidade, pode não ser a solução mais adequada, levando-se em consideração as consequências que dela podem emergir, mantidas as tendências de configuração urbana atuais de produção espacial: congestionamentos, poluição do ar, carência de áreas verdes e de lazer públicos tratados próximos às residências, com mudanças na forma de insolação e direcionamento dos ventos, além da própria relação de vizinhança, podendo conduzir a interferências na qualidade do espaço residencial e, em decorrência disso, na qualidade de vida da população.

\section{Referências}

ACIOLY Jr., C.; DAVIDSON, F. Densidade urbana: um instrumento de planejamento e gestão urbana. Trad. Claúdio Acioly. Rio de Janeiro: Mauad, 1998.

ALVES, S. R. Densidade Urbana: compreensão e estruturação do espaço urbano nos territórios de ocupação dispersa. 2011. 101 f. Dissertação (Mestrado em Arquitetura) Universidade Técnica de Lisboa, Lisboa, 2011.

CARO, C. M.; RIVAS, J. L. Arquitetura urbana: elementos de teoria y diseño. 2. ed. Madrid: Bellisco, 1990.

CARVALHO, H.; CORBELlA, O.; DIAS, F. G. Repercussões negativas no clima da cidade de João Pessoa PB devidas ao escalonamento dos edifícios na sua orla marítima. Arquitextos, v. 7, n. 082.05, mar. 2007. Disponível em: <http://www.vitruvius.com.br/revistas/read/arquitextos/07.082/264>. Acesso em: 1 set. 2011.
GILHAM, O. The limitless city: a primer on the urban sprawl debate. London: Island Press, 2002.

GIMÉNEZ, H. M. M. A verticalização de Maringá: o caso do novo centro: uma urbanização do possível. 2007. 120 f. Dissertação (Mestrado em Geografia) — Universidade Estadual de Maringá, 2007.

GROPIUS, W. Bauhaus: Novarquitetura. São Paulo: Perspectiva, 1977.

HERCULANO, S. A. Qualidade de vida e seus indicadores. In: HERCULANO, S. A. et al. (Org.). Qualidade de vida e riscos ambientais. Niterói: Eduff, 2000.

HOLANDA, A. de. Roteiro para construir no Nordeste. Recife: Programa de Pós-Graduação em Desenvolvimento Urbano da Faculdade de Arquitetura da UFPE, 1976.

KIEFER, F. Estudo de verticalização da cidade: o caso de um bairro de Porto Alegre. 2006. Relatório de Pesquisa Centro Universitário Ritter dos Reis, 2006.

LAPA, T. A. Grandes cidades constroem-se com edifícios grandes? Recife: Editora da UFPE, 2011.

LE CORBUSIER. Planejamento urbano. São Paulo: Perspectiva, 1984.

LEE, J. Quality of life and semipublic spaces in highrise mixeduse housing complexes in South Korea. Journal of Asian Architecture and Building Engineering, v. 10, n. 1, p. 149-156, 2011.

LEE, J.; JE, H.; BYUN, J. Well-Being index of supertall residential buildings in Korea. Building and Environment, v. 46, n. 5, p. 1184-1194, May 2011.

MYERS, N. The biodiversity challenge: expanded hot spots analysis. The Environmentalist, n. 10, p. 243-256, 1990.

NUCCI, J. C. Qualidade ambiental e adensamento urbano. Curitiba: Edição do autor, 2008. Disponível em: <http:// www.geografia.ufpr.br/laboratorios/labs/arquivos/qldade_amb_aden_urbano.pdf $>$. Acesso em: 1 jun. 2011.

PANERAI, P. et al. Urban forms: the death and life of the urban block. Oxford: Architectural Press, 2008.

PEDRO, J. B. Definição e avaliação da qualidade arquitetônica habitacional. In: SEMINÁRIO INTERNACIONAL NUTAU, 2002, São Paulo. Anais... São Paulo: NUTAU, 2002. p. 95-111.

PREFEITURA MUNICIPAL DE JOÃO PESSOA. Código de Urbanismo. João Pessoa: PMJP, 2001. 
RUEDA, S. Lá construcion de la ciudad sostenible. 1996. Disponível em: <http://habitat.aq.upm.es/cs/>. Acesso em: 1 fev. 2011.

RYKWERT, J. A sedução do lugar: a história e o futuro da cidade. São Paulo: Martins Fontes, 2004.

SCUSSEL, M. C. B. 0 lugar de morar em Porto Alegre: uma abordagem para avaliar aspectos de qualificação do espaço residencial, à luz de princípios de sustentabilidade. 2007. 312 f. Tese (Doutorado em Engenharia Civil) Universidade Federal do Rio Grande do Rio Grande do Sul, Porto Alegre, 2007.

SCUSSEL, M. C. B.; SATTER, M. A. Cidades em (trans)formação: impacto da verticalização e densificação na qualidade do espaço residencial. Ambiente Construído, v. 10, n. 3 , p. $137-150,2010$.

SILVEIRA, F. A. Impacto da verticalização na qualidade do espaço residencial: um estudo no bairro de Tambaú, na Cidade de João Pessoa - PB. 2011. 182 f. Dissertação (Mestrado em Arquitetura e Urbanismo) - Universidade Federal da Paraíba, 2011.

SOCCO, C. et al. S.I.S.Te.R.: Sistema di Indicatori per la Sostenibilitá del Territorio Reggiano. Reggio Emilia: Comune/OCS, 2002.
VASCONCELLOS, E. A. Transporte urbano, espaço e equidade: análise das políticas públicas. São Paulo: Annablume, 2001.

VASCONCELLOS, C. Fotógrafo registra o Brasil do alto, a bordo de helicóptero. 2008. Disponível em: <http:// viagem.uol.com.br/album/cassiovasconcellos_brasil_album.htm\#fotoNav=59>. Acesso em: 5 mar. 2008.

VILLAÇA, F. Espaço intraurbano no Brasil. São Paulo: Studio Nobel, 2001.

YEANG, K. Reinventing the skyscraper: a vertical theory of urban design. Chichester; Hoboken: Wiley-Academy, 2002.

Recebido: $16 / 10 / 2013$

Received: 10/16/2013

Aprovado: 02/04/2014

Approved: 04/02/2014 